Haney Margaret (Orcid ID: 0000-0002-1220-9528)

Haney, M.

\title{
Guanfacine Decreases Symptoms of Cannabis Withdrawal in Daily Cannabis Smokers
}

Margaret Haney, Ph.D, Ziva D. Cooper, Ph.D, Gillinder Bedi, D.Psych. Evan Herrmann, Ph.D, Sandra D. Comer, Ph.D, Stephanie Collins Reed, Ph.D., Richard W. Foltin, Ph.D, Frances R. Levin, M.D.

Division on Substance Abuse, New York State Psychiatric Institute and Department of Psychiatry, College of Physicians and Surgeons of Columbia University, 1051 Riverside Drive, Unit 120, New York, NY 10032, U.S.A

Address Correspondence to:

Margaret Haney, Ph.D.

Professor of Clinical Neurobiology

New York State Psychiatric Institute

College of Physicians and Surgeons of Columbia University

1051 Riverside Dr., Unit 120

New York, NY 10032, U.S.A

Phone (646) 774-6153

e-mailmh235@columbia.edu

Running Head: Guanfacine Decreases Cannabis Withdrawal

This is the author manuscript accepted for publication and has undergone full peer review but has not been through the copyediting, typesetting, pagination and proofreading process, which may lead to differences between this version and the Version of Record. Please cite this article as doi: $10.1111 / \mathrm{adb} .12621$

This article is protected by copyright. All rights reserved. 
The $\alpha 2 \mathrm{a}$-adrenergic agonist, lofexidine, reduced cannabis withdrawal-related sleep disruption in the laboratory, but side effects (e.g., fatigue, hypotension) limit its utility as a treatment for cannabis use disorder (CUD). This study tested the potential efficacy and tolerability of a daily bedtime administration of the FDA-approved $\alpha 2$ a-adrenergic agonist, guanfacine, in a human laboratory model of CUD. Daily, nontreatment-seeking cannabis smokers (13M, 2F) completed a within-subject study comprising two 9-day inpatient study phases. Each phase tested the effects of daily placebo or immediate-release guanfacine ( $2 \mathrm{mg}$ ) on cannabis intoxication (5.6\% THC; 2 days), withdrawal (4 days of abstinence) and subsequent 'relapse' (3 days of cannabis self-administration). Ratings of mood, sleep, cardiovascular effects, food intake, psychomotor performance and cannabis selfadministration were assessed. An outpatient phase preceded each inpatient phase for medication clearance or dose induction. Under placebo medication conditions, cannabis abstinence produced significant withdrawal, including irritability, sleep disruption, and anorexia. Guanfacine reduced ratings of irritability and improved objective measures of sleep during cannabis withdrawal relative to placebo, but did not reduce cannabis self-administration. Guanfacine was well tolerated, with little evidence of fatigue and only small decreases in blood pressure: no dose was held due to hypotension. Thus, a single daily administration of guanfacine at bedtime improved sleep and mood during cannabis withdrawal relative to placebo. This positive signal supports further studies varying the guanfacine dose, formulation or frequency of administration, or combining it with other medications to increase the likelihood of having an impact on cannabis use. 
Recent epidemiologic data show that approximately $30 \%$ of individuals in the United States smoking cannabis within the past year met criteria for Cannabis Use Disorder (CUD), but only a small percentage $(\sim 13 \%)$ ever seeks treatment for their symptoms (Hasin et al., 2015, 2016). And for those who do seek treatment, outcomes are usually poor: few achieve long-term abstinence, whether receiving behavioral therapy (e.g., Copeland and Swift 2009; MTPRG, 2004; Budney et al., 2006; Kadden et al., 2007; Carroll et al., 2012) or participating in randomized placebo-controlled pharmacologic trials (e.g., McRae-Clark et al., 2015; Levin et al., 2011, 2016; Weinstein et al., 2014; Gray et al., 2017). There is a clear need to develop effective treatments for individuals with CUD.

One factor contributing to the difficulty achieving abstinence is a cannabis withdrawal syndrome (Budney et al., 2008, Allsop et al., 2012, Haney et al., 2013), comprising a time-dependent, pharmacologically-specific increase in negative mood (e.g., feeling irritable), decrease in food intake, and disrupted sleep following the abrupt cessation of daily cannabis use (Haney et al., 1999, 2003, 2004; Hart et al., 2002; Budney et al. 2004, 2006). Thus, one strategy to reduce cannabis relapse is to target cannabis withdrawal symptoms pharmacologically. We have conducted several placebocontrolled, inpatient laboratory studies testing this strategy and have observed a range of outcomes (see Balter et al., 2014; Brezing and Levin, 2018): Non-cannabinoid medications were shown to have no effect (baclofen; Haney et al., 2010), to worsen mood during cannabis withdrawal (bupropion, divalproex; Haney et al., 2001, 2004), or to selectively improve a subset of cannabis withdrawal symptoms, such as sleep disruption, anorexia (mirtazapine, quetiapine; Cooper et al., 2012; Haney et al., 2010) and anxiety (nefazodone; Haney et al., 2003). To date, cannabinoid receptor agonists (nabilone, dronabinol, nabiximols) have been the most promising, providing wide-ranging reduction 
in cannabis withdrawal symptoms (mood, sleep, food intake), both in the laboratory (Haney et al., 2004, 2008, 2013; Budney et al., 2007; Vandrey et al., 2013; Herrmann et al., 2016) and in clinical settings (Levin et al., 2011; Allsop et al., 2014). Dronabinol and nabiximols have not been shown to reduce cannabis use (Haney et al., 2008, Hart et al., 2002, Levin et al., 2011; Allsop et al., 2014), but nabilone consistently decreases cannabis self-administration in the laboratory (Haney et al., 2013; Herrmann et al., 2016), warranting testing in a clinical setting.

We have also tested the $\alpha 2 \mathrm{a}$ adrenergic receptor agonist, lofexidine, based on preclinical data showing that cannabinoid abstinence is associated with noradrenergic hyperactivity, and that $\alpha 2$ receptor agonists decrease noradrenergic cell firing and symptoms of precipitated tetrahydrocannabinol (THC) withdrawal (see Hart 2005; Carter 1997; Lichtman et al. 2001). Similarly, we found that lofexidine both improved sleep during cannabis withdrawal and decreased a laboratory model of cannabis relapse (Haney et al., 2008). Because of its short half-life, lofexidine was administered four times/day (0.6 mg, QID), a dosing regimen feasible in an inpatient setting but impractical clinically. In fact, in a randomized, placebo-controlled clinical trial for CUD, lofexidine was poorly tolerated even with less frequent dosing and at a lower target dose (0.6 mg TID), with $40 \%$ of patients experiencing dizziness and fatigue (Levin et al., 2016).

Yet given that $\alpha 2$-adrenergic agonism had promising effects in the inpatient setting, the objective of this placebo-controlled, inpatient study was to test our hypothesis that once-daily nighttime administration of the $\alpha 2$-adrenergic agonist, guanfacine, would reduce cannabis withdrawal and a laboratory measure of relapse while producing little evidence of sedation or hypotension. 
Guanfacine hydrochloride (Tenex $\left.{ }^{\circledR}\right)$, FDA approved for the treatment of hypertension, peaks in the serum in 1-4 hours (Strange 2008), and is given multiple times per day for this indication. Our aim, however, was to give guanfacine only at bedtime, to take advantage of the 'side effect' of fatigue without producing daytime side effects.

\section{Materials and Methods}

\section{Participants:}

Eligible participants were healthy, normotensive, 21-53 years of age and current cannabis smokers (minimum of 2 cannabis cigarettes/day, 6 days/week; confirmed with urine toxicology). Exclusion criteria included: (1) current use of any other illicit substances, as verified by urine toxicology, (2) meeting DSM 5 criteria for any current psychiatric disorder requiring medical intervention, (3) daily use of prescription or non-prescription medications, (4) seeking treatment for cannabis use (although all expressed ambivalence about their cannabis use, either in a willingness to reduce cannabis use or consider treatment in the future), and (5) a history of heart disease or cardiac risk factors (e.g., arrhythmias). Eligibility assessments included a physical and psychiatric evaluation, electrocardiogram, urinalysis, urine toxicology, and blood chemistry panels. Participants signed a consent form approved by The New York State Psychiatric Institute (NYSPI) Institutional Review Board, which described the study, outlined possible risks, and indicated that a range of FDAapproved medications or placebo might be administered. Prior to study onset, participants completed two, 3-4 hour training sessions; no cannabis was administered during training sessions. All were compensated for participation. 


\section{Procedures:}

Participants, in groups of 3 or 4, lived in a residential laboratory in NYSPI, with four private rooms, a recreational area, two bathrooms and two vestibules. Output from a video- and audiomonitoring system terminating in a control room allowed for continuous observation (see Haney et al., 1999). The study comprised two 9-day inpatient phases, with each phase testing a different medication condition (guanfacine vs. placebo); Table 1 portrays the study timeline for a representative guanfacine phase. A 10-day outpatient phase preceded each inpatient phase to allow for dose titration (target dose: $2 \mathrm{mg}$ ) or medication washout. While outpatient, participants came to the laboratory every 48 hours for measures of blood pressure, cannabis use, side effects and medication compliance (urine under ultraviolet light to detect the riboflavin included in capsules). Before each inpatient stay, participants completed a 'sample' cannabis administration session in order to familiarize them with the cannabis smoking procedures and the cannabis strength available for self-administration during the study.

During inpatient phases, participants completed a sleep scale and a mood scale upon awakening each day at 0815. Between 0915-1645, they completed six 30-min subjective drug effects and psychomotor task batteries. The recreation area was available at lunchtime and from 1700-2200. At 2330, participants completed a final mood scale and were given $\$ 50$ in faux money representing a portion of their daily earnings. They were told that this money could be used to purchase individual cannabis puffs on self-administration days, or exchanged for cash upon study completion. Lights were turned off by 2400 . 


\section{Cannabis Administration}

Each participant received a single cannabis cigarette (5.6\% THC, ca. $800 \mathrm{mg}$; provided by NIDA) at each smoking occasion. Cannabis was administered using a paced-puffing smoking procedure, where inhalation duration, time spent holding smoke in the lungs, and inter-puff interval was timed (Foltin et al., 1987). Each morning, participants were informed if cannabis (1) was available for selfadministration, (2) was going to be experimenter-administered (at no cost), or (3) was not available that day.

During experimenter-administered days (first two days of each inpatient phase), participants smoked 3 puffs of cannabis at 1000,1130,1300,1430, 1600 and 2200. The purpose of these days was to standardize cannabis exposure prior to abstinence and to test the effects of guanfacine on cannabis' acute subjective effects. On the subsequent 4 days, no cannabis was available [abstinence], followed by 3 days when cannabis was available for self-administration [relapse]. On selfadministration days, participants could purchase up to 3 puffs of cannabis at each of the 6 dosing times described above using their study earnings. The cost was $\$ 7$ for the first puff of the day, and $\$ 1$ for all subsequent puffs. This laboratory model of relapse is structured so that a return to cannabis self-administration after a period of abstinence is financially costly. Participants make repeated decisions whether to pay for individual puffs of cannabis in an effort to model (not mimic) the decisions faced clinically (Haney et al., 2008, 2010, 2015; Cooper et al., 2012). All self-administered cannabis was smoked in private so that the participants were blind to each other's choices. Money 
earned each inpatient day that was not spent on cannabis was given to the participants at study conclusion.

\section{Capsule Administration}

The NYSPI Research Pharmacy packaged guanfacine and placebo in size 00 opaque capsules with riboflavin and lactose filler. Capsule administration was double-blind and the order in which guanfacine and placebo were given was counter-balanced across participants. In the guanfacine condition, participants received $1 \mathrm{mg}$ for 6 days and $1.5 \mathrm{mg}$ for 4 days during the outpatient phase and were instructed to take the medication at bedtime. They received the target dose $(2 \mathrm{mg})$ over the nine inpatient days. While inpatient, dosing occurred at 2230, one hour before bedtime. In the placebo condition, participants took capsules on the same schedule.

During inpatient phases, blood pressure was taken twice per day: after participants had been seated for at least $1 \mathrm{~min}$ and then after they had been standing for $1 \mathrm{~min}$. Capsules were not administered if blood pressure was $<90 / 50$ and there were symptoms of hypotension (e.g., lightheadedness or dizziness), or if heart rate $<50$ or $>110$.

\section{Task Battery and Mood Scales}

Each task battery consisted of a 3-min digit-symbol substitution task (DSST), a 3-min repeated acquisition task (RAT), a 10-min divided attention task (DAT), a 10-min rapid information task (RIT), and an immediate and delayed digit-recall task. The battery measures aspects of learning, memory, vigilance, and psychomotor ability (Foltin et al., 1996).

Participants completed a 44-item computerized subjective-effects questionnaire visual analog 
scale (VAS), comprising a series of 100-mm lines labeled "Not at all" (0 mm) at one end and "Extremely" at the other end 8 times per day. The VAS included mood, physical symptom and drug effect descriptors; participants were instructed to rate the extent to which each descriptor applied to them at that moment. Based on a cluster analysis, we employed arithmetic means of individual item scores to reduce 34 of the 44 items into eight subscales: miserable ("miserable," "depressed"); irritable (“irritable," "angry”); anxious (e.g., "anxious," "on edge," "restless"); bad effect (e.g., “dizzy," "upset stomach”); tired (e.g., "tired," "sleepy”); social (e.g., "friendly," "talkative”); high ("high," "good effect”); and confused (“confused," "forgetful, "can’t concentrate."). We also analyzed individual VAS ratings of drug craving: "I want...Cannabis," "Alcohol," and "Cigarettes." A Drug-Effect Questionnaire (Evans et al., 1995) was administered 45 mins after dosing and the following morning (9 hours and 45 mins after capsule administration) to assess ratings specific to capsule effects.

\section{Food}

Each morning, participants received a box of food containing a wide variety of meal items, snacks and beverages. Frozen meals and additional units of any item were available by request. Participants were instructed to scan custom-designed bar codes whenever they ate or drank, automatically specifying substance and portion. Food was not available between 2330 and 0815 .

\section{Sleep}

Objective measurements of sleep latency and sleep efficiency, defined as the percentage of time spent asleep during the lights-out period (0000-0800), were obtained using the wrist-worn 
Actiwatch Activity Monitoring System (Respironics Company, Bend OR). Subjective ratings of the previous night's sleep were obtained using a 7-item VAS sleep questionnaire completed each morning (Haney et al., 2004).

\section{Tobacco cigarette smoking}

Participants were permitted to smoke cigarettes ad libitum. The number of tobacco cigarettes smoked was recorded by counting cigarette butts in each participant's ashtray each evening.

\section{Data Analysis}

Repeated measures analyses of variance (ANOVA) including two within-subject factors (medication dose, inpatient day) with planned comparisons were used to determine the effect of guanfacine on cannabis withdrawal and relapse relative to placebo. Outcomes included: daily peak subjective-effects ratings, drug craving, objective and subjective sleep measures, food intake (total energy intake, percent macronutrient [fat, protein, carbohydrate], number and caloric content of individual eating occasions, defined as beginning with onset of food consumption and ending at the first pause in food reporting > 10 minutes), body weight, blood pressure, and heart rate, task performance, number of cigarettes smoked per day, and the number of cannabis puffs purchased during the relapse phase. The following planned comparisons were conducted to assess: (a) cannabis withdrawal: during placebo maintenance, initial abstinence (days 1-2) and later abstinence (days 3-4) were compared to days of experimenter-administered cannabis (mean of 2 days), (b) guanfacine effects on cannabis withdrawal: the effects of guanfacine were compared in initial abstinence (days 12) and later abstinence (days 3-4) to placebo, (c) guanfacine effects on cannabis: the effect of 
cannabis administration (mean of 2 days) was compared under guanfacine and placebo maintenance (Table 1). Effects of guanfacine on the frequency of side effects were assessed using Sign Tests. Significance was determined at $\alpha=0.05$. Huynh-Feldt corrections were used, when appropriate.

\section{Results}

\section{Participant Characteristics}

Table 2 presents demographic and substance use data on the 15 cannabis smokers who completed the study. Note, repeated-measures, within-subjects designs, result in substantial correlations between levels, and are a powerful statistical approach. Based on a previous study (Haney et al., 2013b), a sample size of 15 study completers provide a power of over $90 \%$ to detect changes in cannabis selfadministration and subjective effects. In addition to the 15 study completers, three male participants began the study as one cohort, but two were lost to contact after completing the first inpatient phase, so the study was cancelled and the third member of the cohort was discharged. In order to ensure having a cohort of four participants for the inpatient study phase, we over-enrolled at the start of outpatient dosing. A total of 10 additional volunteers began outpatient dosing. Since the laboratory can only accommodate four participants at a time, when more than four participants were available to start the first inpatient phase, we selected those who had been most reliable with their outpatient appointments to enter as inpatients.

\section{Subjective-Effects Ratings and Drug Craving:}

Figure 1 and Table 3 portray outcome as a function of cannabis and guanfacine dose; note, degrees of freedom for all analyses were $(1,112)$ unless otherwise indicated. In terms of cannabis 
withdrawal symptoms, cluster ratings of 'irritable' significantly increased by days 3-4 of abstinence relative to cannabis administration $[\mathrm{F}=33.29, \mathrm{p}<.0001]$, and this effect was reduced by guanfacine $[\mathrm{F}=10.73, \mathrm{p}<.01]$ compared to placebo (Fig. 1). There was also a significant reduction in cluster ratings of 'high' during days $1-2[\mathrm{~F}=207.55, \mathrm{p}<.001]$ and days $3-4[\mathrm{~F}=203.50, \mathrm{p}<.001]$ of abstinence; guanfacine had no effect on ratings of 'high' (Table 3). No other cluster rating or ratings of cannabis craving were significantly affected by cannabis abstinence or by guanfacine. Guanfacine also did not modulate cannabis' direct effects on mood or craving during days of cannabis administration relative to placebo.

Capsule Ratings: Cannabis abstinence was associated with significant $(\mathrm{p}<0.02)$ changes in placebo capsule ratings: participants rated that they 'liked' the capsules less [days 1-2, F=16.64; days 3-4, F=21.48], rated them as less 'good' [days 1-2, F=22.36; days 3-4, F=22.36] and 'strong' [days 12, F=15.35; days 3-4, F=13.94], and were less willing to 'take them again' [days 1-2, F=11.96; days $3-4, F=17.64]$ when abstinent as compared to ratings on cannabis administration days. Guanfacine had no significant effect on capsule ratings during abstinence, but increased ratings of capsule strength on days of cannabis administration relative to placebo ( $\mathrm{F}=7.27$; data not shown).

\section{Objective and Subjective Sleep Data}

Figure 2 and Table 2 show that cannabis abstinence was associated with significant disruptions in sleep ( $\mathrm{p}<0.05$ ). In terms of objective measures, sleep efficiency was decreased [days 1-2, F=26.71; days $3-4, F=10.05$ ] while the latency to fall asleep increased [days 1-2, F=28.39] during abstinence relative to days of cannabis administration (Fig. 2). Guanfacine attenuated these withdrawal 
symptoms, increasing sleep efficiency [days 1-2, F=6.06] and reducing sleep latency [days 1-2, $\mathrm{F}=14.03]$ relative to placebo. Guanfacine improved withdrawal-related sleep disruption but did not alter objective measures of sleep during days of cannabis administration relative to placebo.

In terms of subjective sleep measures, ratings of 'fell asleep easily' [days 1-2, F=21.26; days 34, F=16.18] and 'sleep satisfaction' [days 1-2, F=20.13; days 3-4, F=5.98] were significantly lower during abstinence (Fig. 2), as were ratings of 'slept well' [days 1-2, F = 11.75], 'clear-headed' [days 1-2, F=7.48; days 3-4, F = 11.32] and estimated hours slept [days $1-2, \mathrm{~F}=7.45$ ] compared to cannabis administration (Table 3). Ratings of 'woke often' were significantly increased during initial abstinence relative to cannabis administration [Table 3: days 1-2, F = 4.32]. Guanfacine did not significantly alter subjective ratings of sleep, either during cannabis abstinence or during days of cannabis administration relative to placebo.

\section{Food intake and Body Weight}

Table 3 shows that cannabis abstinence robustly decreased daily caloric intake [days 1-2, $\mathrm{F}=62.09$; days $3-4, \mathrm{~F}=51.52, \mathrm{p}<0.001]$ compared to cannabis administration; participants had fewer eating occasions during abstinence relative to cannabis administration [days 1-2, F=34.71; days 3-4, $\mathrm{F}=31.82]$, although the number of calories consumed during each eating occasion and the ratio of macronutrients consumed was not significantly altered by abstinence. Body weight was also reduced during cannabis abstinence, with participants losing an average of $1.4 \mathrm{~kg}$ during initial abstinence [days $1-2, F=40.07$ ] and $2.5 \mathrm{~kg}$ by later abstinence [days 3-4, F=118.98] relative to days of cannabis 
administration. Guanfacine had no effect on any food intake measures or on body weight, either during cannabis abstinence or during days of cannabis administration relative to placebo.

\section{Blood pressure and heart rate:}

As shown in Figure 3, cannabis abstinence significantly increased blood pressure $(\mathrm{p}<0.001)$, both during initial (days 1,2: $\mathrm{SP}[\mathrm{F}=13.61]$, $\mathrm{DP}[\mathrm{F}=12.26]$ ) and later abstinence (days 3,4: $\mathrm{SP}$ [F= 27.41], DP [ $F=12.70]$ ) relative to cannabis administration, and guanfacine significantly reversed this effect $(\mathrm{p}<0.001)$ : Relative to placebo, guanfacine decreased blood pressure during both initial (days 1,2: $\mathrm{SP}[\mathrm{F}=41.12]$, DP $[\mathrm{F}=31.47]$ ) and later abstinence (days 3,4: SP [F=55.49], DP [F= 28.90]). Heart rate increased in later abstinence (days 3,4: [F=19.69]) relative to cannabis administration, and guanfacine significantly reduced this effect (days 3,4: [F=15.58]). Guanfacine also decreased blood pressure on days of cannabis administration ( $\mathrm{SP}$ [F=36.31], $\mathrm{DP}$ [F=26.31].

\section{Task Performance:}

There were few significant effects of either cannabis condition or guanfacine on task performance. Table 3 shows that cannabis abstinence was associated with significantly $(\mathrm{p}<0.05)$ improved performance on the DSST (increased correct entries) [days 1-2, F=11.90; days 3-4, F=7.77) and on the DAT (increased maximum speed) [days 1-2, F=6.16]) relative to cannabis administration. Guanfacine improved DAT performance during cannabis abstinence [days 3-4, F=13.25]) relative to placebo, but had no other significant effects.

\section{Tobacco cigarette smoking:}


Among tobacco cigarettes smokers $(n=12)$, cannabis abstinence was associated with an increase in the number of tobacco cigarettes smoked [days $1-2, \mathrm{~F}=14.12$; days $3-4, \mathrm{~F}=23.07$ ] and a decrease in craving for cigarettes [days $1-2, \mathrm{~F}=11.38$; days $3-4, \mathrm{~F}=11.04, \mathrm{p}<0.005$ ] relative to cannabis administration. Guanfacine significantly increased craving for tobacco cigarettes during cannabis abstinence [days 1-2, F = 19.03; days 3-4, F=9.10, $\mathrm{p}<0.01$ ], but did not alter the number of tobacco cigarettes smoked, either during abstinence or during cannabis administration relative to placebo (Table 3).

\section{Cannabis Relapse}

Under placebo conditions, $53 \%$ of participants relapsed to cannabis use, averaging $5.9 \pm 1.0$ puffs/day. Guanfacine had no effect on the number of participants who relapsed (53\%) or the mean number of cannabis puffs self-administered per day $(6.1 \pm 1.1)$ relative to placebo.

\section{Side Effects}

Table 4 shows the frequency and number of individuals reporting side effects during the outpatient and inpatient phases. Sign Tests revealed no significant effect of guanfacine dose on the frequency of side effects reported during either outpatient or inpatient phases (all p values $>0.35$ ).

\section{Discussion}

This study shows that a daily bedtime administration of immediate-release guanfacine ( $2 \mathrm{mg}$ ) significantly reduced irritability and improved objective measures of sleep during cannabis withdrawal relative to placebo. Guanfacine produced small but significant decreases in blood 
pressure and heart rate but was well tolerated, producing none of the sedation, dizziness or altered food intake observed with lofexidine, the other $\alpha 2$ a-receptor agonist investigated as a potential treatment for CUD (Haney et al., 2008; Levin et al., 2016).

To our knowledge, guanfacine is the first non-cannabinoid agonist to reduce cannabis withdrawal-related irritability. Did guanfacine improve mood by improving sleep? Abstinencerelated sleep disruptions occurred early in abstinence, before the onset of worsened mood. Yet medications such as mirtazapine, quetiapine and zolpidem robustly reversed withdrawal-related sleep disruption and had no effect on mood during withdrawal (Haney et al., 2010; Cooper et al., 2012; Herrmann et al., 2016), suggesting that sleep improvement alone is not sufficient to improve mood during cannabis abstinence. Guanfacine has also been shown to reduced negative affect during early abstinence from cocaine (Fox et al., 2015), and to reduce frustration in children with ADHD (Hunt et al., 1995), suggesting the medication might act directly on mood. Schulz and colleagues (2013) suggest that guanfacine improves emotion regulation during periods of noradrenergic dysfunction, as likely occurs during cannabis withdrawal, by acting in prefrontal cortical regions rich in $\alpha 2 \mathrm{a}$ receptors.

Despite reductions in certain withdrawal symptoms, guanfacine did not reduce cannabis selfadministration, which we hypothesize is the best human laboratory predictor of a clinically efficacious medication for substance use treatment (Haney and Spealman, 2008; Comer et al., 2008; Haney 2009). Lofexidine, by contrast, decreased cannabis self-administration in the laboratory after abstinence. Lofexidine was also administered repeatedly throughout the day, with concomitant 
daytime fatigue. Our objective in this study was to reduce these side effects, but it may be that a once-daily nighttime administration of guanfacine $(2 \mathrm{mg})$ is too low a dose to impact decisions to smoke cannabis made over the course of the day. In a study testing potential treatments for tobacco cessation, McKee and colleagues (2015) saw promising effects with a higher dose of immediaterelease guanfacine (3 mg) administered in split doses twice/day (dosing was titrated over 3 weeks). Guanfacine reduced a stress-induced laboratory measure of a cigarette lapse, reduced the number of cigarettes smoked and improved treatment retention over a four-week treatment period, although it did not significantly increase the number of participants achieving abstinence. Importantly, twice per day dosing of guanfacine was well tolerated: Side effects such as dry mouth and fatigue were rated as minimal or mild and no participant required a dose adjustment (McKee et al., 2015). Overall, these findings support studies testing a higher daily dose of guanfacine, including administration during waking hours to reduce cannabis self-administration while still facilitating sleep.

Consistent with earlier studies (Vandrey et al., 2011), cannabis withdrawal alone produced small but significant increases in heart rate and blood pressure, but these increases do not appear to be clinically significant in healthy, normotensive cannabis smokers (Haney et al., 2008). Guanfacine reduced withdrawal-related increases in heart rate, and reduced blood pressure whether participants were smoking cannabis or were abstinent. None of these changes were associated with dizziness or exceeded our safety criteria for medication administration.

Guanfacine did not significantly impact any other cannabis withdrawal symptom. As in earlier studies, daily caloric intake dropped by about $1500 \mathrm{kcal} /$ day during abstinence as compared to 
ongoing cannabis use, mirrored by decreased body weight (Haney et al., 2010, 2013; Cooper et al., 2012). Guanfacine, unlike lofexidine, did not worsen abstinence-related anorexia and weight loss (Haney et al., 2008), but neither did it ameliorate it. Similarly, guanfacine had little overall effect on psychomotor task performance, contrasting with lofexidine, which worsened task performance (Haney et al., 2008). This may also reflect the absence of daytime guanfacine administration. Guanfacine also produced small but significant increases in tobacco cigarette craving during cannabis abstinence relative to placebo, but did not increase the number of cigarettes smoked. This counters data cited above showing that guanfacine shows promise for the treatment of tobacco dependence. This suggest that dual cannabis and tobacco smokers respond differently to guanfacine vis a vis their tobacco cigarette smoking relative to those who are not cannabis users.

In terms of study limitations, we suspect that the primary limitation is the guanfacine dose: Given the lengthy study design, only one active dose was tested, and it was likely too low to meaningfully influence cannabis self-administration. An additional limitation is that participation was largely male, a common feature of studies with a long inpatient stay, but which limits the generalizability of the findings. Finally, our working hypothesis is that medications that reduce cannabis self-administration in nontreatment-seeking cannabis smokers under conditions of financial cost predict medication effects in a treatment-seeking population. But in lieu of an efficacious medication to treat CUD, we cannot confirm the validity of our model. It is worth noting that the results reported across a range of medications tested in the human laboratory have been almost entirely consistent with clinical trial outcome (Brezing and Levin, 2018). But it remains possible that guanfacine would have more salutary effects in individuals motivated to reduce their cannabis use. 
In summary, medications are a needed option to improve outcome for the treatment of CUD. In this laboratory model, daily guanfacine administration $(2 \mathrm{mg})$ at bedtime produced several positive signals: the medication was well-tolerated, significantly improved sleep, and reduced negative mood during cannabis withdrawal relative to placebo. Future studies varying the daily dose of guanfacine administration, testing extended-release guanfacine alone or combining guanfacine with other medications are needed to optimize effects on cannabis withdrawal and cannabis use, and thereby increase the likelihood of impacting clinical treatment of CUD. 


\section{Funding and Disclosures}

Dr. Haney's research is funded by NIDA. She and Dr. Cooper have received partial salary support for an investigator-initiated study from Insys Therapeutics Inc. testing the effects of cannabidiol on laboratory measures of pain. The other authors have no potential conflicts of interest.

\section{Authors Contributions}

MH and FRL were responsible for the study concept and design, and MH drafted the manuscript. EH assisted with statistical analysis. All authors performed essential study procedures (e.g., cannabis administration, overseeing research staff) and all authors critically reviewed content and approved the final version for publication.

\section{Acknowledgments:}

The U.S. National Institute on Drug Abuse (NIDA) supported this research (5U54DA037842) and supplied the cannabis cigarettes. We are grateful to Philip Kamilar-Britt, Mikiko Thelwell and Amanda Erakky for their expert assistance in data collection. We would also like to thank Aidan Hampson, Ph.D. (NIDA) for early discussions of study design.

\section{References:}

Allsop DJ, Copeland J, Norberg MM, Fu S, Molnar A, Lewis J, Budney AJ (2012). Quantifying the clinical significance of cannabis withdrawal. PLoS ONE, 7(9): e44864.

Allsop DJ, Copeland J, Lintzeris N, Dunlop AJ, Montebello M, Sadler C, Rivas GR, Holland RM, Muhleisen P, Norberg MM, Booth J, McGregor IS (2014). Nabiximols as an agonist 
Haney, M.

replacement therapy during cannabis withdrawal: a randomized clinical trial. JAMA Psychiatry 71(3): 281-291.

Balter RE, Cooper ZD, Haney M (2014). Novel pharmacologic approaches to treating cannabis use disorder. Current Addiction Reports, 1(2): 137-143.

Brezing CA, Levin FR (2018) The current state of pharmacological treatment of Cannabis Use Disorder and withdrawal. Neuropsychopharm Rev 43: 173-194.

Budney AJ, Hughes JR, Moore BA, Vandrey R (2004). Review of the validity and significance of cannabis withdrawal syndrome. Am J Psychiatry 161: 1967-1977.

Budney AJ, Moore BA, Rocha HL, Higgins ST (2006). Clinical trial of abstinence-based vouchers and cognitive-behavioral therapy for cannabis dependence. J Consult Clin Psychol 74: 307-316.

Budney AJ, Vandrey RG, Hughes JR, Moore BA, Bahrenburg B (2007). Oral delta-9

tetrahydrocannabinol suppresses cannabis withdrawal symptoms. Drug Alcohol Depend 86: 2229.

Budney AJ, Vandrey RG, Hughes JR, Thostenson JD, Bursac Z (2008). Comparison of cannabis and tobacco withdrawal: severity and contribution to relapse. J Substance Abuse Treatment 35: 362368.

Carroll KM, Nich C, Lapaglia DM, Peters EN, Easton CJ, Petry NM (2012). Combining cognitive behavioral therapy and contingency management to enhance their effects in treating cannabis dependence: less can be more, more or less. Addiction 107: 1650-9.

This article is protected by copyright. All rights reserved. 
Carter AJ (1997). Hippocampal noradrenaline release in awake, freely moving rats is regulated by alpha-2 adrenoceptors but not by adenosine receptors. J Pharmacol Exp Ther 281: 648-654.

Comer SD, Ashworth JB, Foltin RW, Johanson CE, Zacny JP, Walsh SL (2008). The role of human drug self-administration procedures in the development of medications. Drug Alcohol Depend 96: 1-15.

Cooper ZD, Foltin RW, Hart CL, Vosburg SK, Comer SD, Haney M (2012). A controlled human laboratory study investigating the effects of quetiapine on cannabis withdrawal and relapse in daily cannabis smokers. Addiction Biology, 18(6): 993-1002.

Copeland J, Swift W (2009). Cannabis use disorder: epidemiology and management. International Review of Psychiatry 21(2): 96-103.

Evans SM, Foltin RW, Levin FR, Fischman MW (1995). Behavioral and subjective effects of DN2327 (pazinaclone) and alprazolam in normal volunteers. Behav Pharmcol 6:176-186.

Foltin RW, Fischman MW, Pedroso JJ, Pearlson GD (1987). Cannabis and cocaine interactions in humans: cardiovascular consequences. Pharmacol Biochem Behav 28: 459-464.

Foltin RW, Haney M, Comer SD, Fischman MW (1996). Effects of fenfluramine in food intake, mood, and performance of humans living in a residential laboratory. Physiol Behav 59: 295305.

Fox H, Sofuoglu M, Sinha R (2015). Guanfacine enhances inhibitory control and attentional shifting in early abstinent cocaine-dependent individuals. Psychopharmacol 29(3): 312-323. 
Haney, M.

Gray KM, Sonne SC, McClure EA, Ghitza UE, Matthews AG, McRae-Clark AL, Carroll KM, Potter JS, Wiest K, Mooney LJ, Hasson A, Walsh SL, Lofwall MR, Babalonis S, Lindblad RW, Sparenborg S, Wahle A, King JS, Baker NL, Tomko RL, Haynes LF, Vandrey RG, Levin FR (in press). A randomized placebo-controlled trial of $\mathrm{N}$-acetylcysteine for cannabis use disorder in adults. Drug Alcohol Depend 177: 249-257

Haney M (2009). Self-administration of cocaine, cannabis and heroin in the human laboratory: benefits and pitfalls. Addict Biol 14: 9-21.

Haney M, Bedi G, Cooper ZD, Glass A, Vosburg SK, Comer SD, Foltin RW (2013). Predictors of marijuana relapse in the human laboratory: robust impact of tobacco cigarette smoking status. Biological Psychiatry 73: 242-248.

Haney M, Cooper ZD, Bedi G, Vosburg SK, Comer SD, Foltin RW (2013). Nabilone decreases marijuana withdrawal and a laboratory measure of marijuana relapse. Neuropsychopharmacology 38(8): 1557-1565.

Haney M, Hart CL, Vosburg SK, Comer SD, Reed SC, Cooper ZD, Foltin RW (2010). Effects of baclofen and mirtazapine on laboratory model of cannabis withdrawal and relapse.

Psychopharmacol 211: 233-244.

Haney M, Hart CL, Vosburg SK, Comer SD, Reed SC, Foltin RW (2008). Effects of THC and lofexidine in a human laboratory model of cannabis withdrawal and relapse. Psychopharmacol 197: $157-168$.

This article is protected by copyright. All rights reserved. 
Haney M, Hart CL, Vosburg SK, Nasser J, Bennett A, Zubaran C, Foltin RW (2004). Marijuana withdrawal in humans: effects of oral THC or divalproex. Neuropsychopharmacol 29: 158-170.

Haney M, Hart CL, Ward AS, Foltin RW (2003). Nefazodone decreases anxiety during marijuana withdrawal in humans. Psychopharmacol 165(2): 157-165.

Haney M, Ramesh D, Glass A, Pavlicova M, Bedi G, Cooper Z D (2015). Naltrexone maintenance decreases cannabis self-administration and subjective effects in daily cannabis smokers. Neuropsychopharmacol 40(11): 2489-2498.

Haney M, Spealman R (2008). Controversies in translational research: drug self-administration. Psychopharmacol 199: 403-419.

Haney M, Ward AS, Comer SD, Foltin RW, Fischman MW (1999). Abstinence symptoms following smoked cannabis in humans. Psychopharmacol 141: 395-404.

Haney M, Ward AS, Comer SD, Hart CL, Foltin RW, Fischman MW (2001). Bupropion SR worsens mood during marijuana withdrawal in humans. Psychopharmacol 155(2): 171-179.

Hart CL, Ward AS, Haney M, Comer SD, Foltin RW, Fischman MW (2002). Comparison of smoked cannabis and oral delta(9)-tetrahydrocannabinol in humans. Psychopharmacol 164: 407-415.

Hart CL (2005). Increasing treatment options for cannabis dependence: a review of potential pharmacotherapies. Drug Alcohol Depend 80:147-159.

Hasin DS, Saha TD, Kerridge BT, Goldstein RB, Chou SP, Zhang H, Jung J, Pickering RP, Ruan WJ, Smith SM, Huang B, Grant BF (2015). Prevalence of marijuana use disorders in the United States between 2001-2002 and 2012-2013. JAMA Psychiatry 72(12): 1235-1242.

This article is protected by copyright. All rights reserved. 
Hasin DS, Kerridge BT, Saha TD, Huang B, Pickering R, Smith SM, Jung J, Zhang H, Grant BF (2016). Prevalence and correlates of DSM-5 cannabis use disorder, 2012-2013: findings from the national epidemiologic survey on alcohol and related conditions-III. American Journal of Psychiatry, 173(6): 588-599.

Herrmann ES, Cooper ZD, Bedi G, Ramesh D, Reed SC, Comer SD, Foltin RW, Haney M (2016). Effects of zolpidem alone and in combination with nabilone on cannabis withdrawal and a laboratory model of relapse in cannabis users. Psychopharmacol, 233(13): 2469-2478.

Hunt RD, Arnsten AF, Asbell MD (1995). An open trial of guanfacine in the treatment of attentiondeficit hyperactivity disorder. J Am Acad Child \& Adolescent Psychiatry, 34(1): 50-54.

Kadden RM, Litt MD, Kabela-Cormier E, Petry NM (2007). Abstinence rates following behavioral treatments for cannabis dependence. Addict Behav 32: 1220-1236.

Levin FR, Mariani JJ, Brooks DJ, Pavlicova M, Cheng W, Nunes EV (2011). Dronabinol for the treatment of cannabis dependence: A randomized, double-blind, placebo-controlled trial. Drug and Alcohol Dependence 116(1-3): 142-150.

Levin FR, Mariani JJ, Pavlicova M, Brooks D, Glass A, Mahony A, Nunes EV, Bisaga A, Dakwar E, Carpenter KM, Sullivan MA, Choi JC (2016). Dronabinol and lofexidine for cannabis use disorder: a randomized, double-blind, placebo-controlled trial. Drug and Alcohol Dependence 159: 53-60.

Lichtman AH, Fisher J, Martin BR (2001). Precipitated cannabinoid withdrawal is reversed by delta(9)-tetrahydrocannabinol or clonidine. Pharmacol Biochem Behav 69:181-188. 
McKee SA, Potenza MN, Kober H, Sofuoglu M, Arnsten AF, Picciotto MR, Sinha R (2015). A translational investigation targeting stress-reactivity and prefrontal cognitive control with guanfacine for smoking cessation. J Psychopharmacol 29(3): 300-311.
McRae-Clark AL, Baker NL, Gray KM, Killeen T, Hartwell KJ, Simonian SJ (2015). Vilazodone for cannabis dependence: a randomized, controlled pilot trial. The American Journal on Addictions, 25(1): 69-75.

MTPRG (2004). Brief treatments for cannabis dependence: findings from a randomized multisite trial. J Consult Clin Psychol 72: 455-466.

Strange B (2008). Once-daily treatment of ADHD with guanfacine: patient implications. Neuropsychiatric Disease and Treatment 4(3): 499-506.

Schulz KP, Clerkin SM, Fan J, Halperin JM, Newcorn JH (2013). Guanfacine modulates the influence of emotional cues on prefrontal cortex activation for cognitive control. Psychopharmacol 226(2): 261-271.

Vandrey R, Umbricht A, Strain EC (2011). Increased blood pressure after abrupt cessation of daily cannabis use. J Addict Med 5:16-20.

Vandrey R, Stitzer ML, Mintzer MZ, Huestis MA, Murray JA, Lee D (2013). The dose effects of short-term dronabinol (oral THC) maintenance in daily cannabis users. Drug Alcohol Depend 128(1-2): 64-70.

This article is protected by copyright. All rights reserved. 
Weinstein AM, Miller H, Bluvstein I, Rapoport E, Schreiber S, Bar-Hamburger R, Bloch M (2014). Treatment of cannabis dependence using escitalopram in combination with cognitive-behavior therapy: a double-blind placebo-controlled study. Am J Drug Alcohol Abuse 40(1): 16-22. 
Haney, M.

TABLE 1: Representative Timeline for Guanfacine Phase

\begin{tabular}{|c|c|c|c|c|c|c|c|c|c|c|}
\hline \multirow{3}{*}{$\begin{array}{l}\text { Condition } \\
\text { Cannabis }\end{array}$} & \multirow{3}{*}{$\begin{array}{c}\text { Outpatient } \\
\text { ad lib }\end{array}$} & \multicolumn{9}{|c|}{ Inpatient } \\
\hline & & \multicolumn{2}{|c|}{ Experimenter-administered } & \multicolumn{2}{|c|}{ Initial Abstinence } & \multicolumn{2}{|c|}{ Later Abstinence } & \multicolumn{3}{|c|}{ Relapse } \\
\hline & & $\checkmark$ & $\checkmark$ & - & - & - & - & $\checkmark$ & $\checkmark$ & $\checkmark$ \\
\hline Guanfacine ( $m g$ ) & $1.0-1.5$ & 2.0 & & & & & & & & \\
\hline
\end{tabular}

Note: 10-day outpatient phase; lab visits every other day for medication compliance; 9 -day inpatient phase 
TABLE 2: Demographic characteristics of study completers

Number of participants

Race (Black/White/Mixed)

Ethnicity (Hispanic/non-Hispanic)

Age (years)

Education (years)

Cannabis frequency (days/week)

Cannabis quantity (grams/day)

Duration regular cannabis use (years)

Tobacco cigarette smokers (\#)

$$
\text { Cigarettes/day (\#) }
$$

Alcohol drinkers (\#)*

Alcohol: Drinks/week (\#)
$15(13 \mathrm{M} ; 2 \mathrm{~F})$

$12 / 1 / 2$

$4 / 11$

$30.0 \pm 5.8$

$12.2+1.7$

$6.9 \pm 0.3$

$4.7 \pm 3.3$

$13.6 \pm 6.6$

12

$4.4+4.5$

4

$$
2.4 \pm 1.6
$$

Note: Data are presented as means ( \pm standard deviation) or as frequency. *Only included those reporting at least 1 drink/week.

Participants used no drugs other than cannabis, alcohol or tobacco.

This article is protected by copyright. All rights reserved. 
TABLE 3: Mean peak effects during cannabis administration (5.6\% THC) and during days 1-2 and days 3-4 of cannabis abstinence as a function of guanfacine dose $(0,2 \mathrm{mg})$

\begin{tabular}{|c|c|c|c|c|}
\hline & & \multirow{2}{*}{$\begin{array}{c}\text { Cannabis } \\
\text { Administration }\end{array}$} & \multicolumn{2}{|c|}{ Cannabis Abstinence } \\
\hline & & & days 1-2 & days 3-4 \\
\hline \multirow[t]{2}{*}{ High: } & $0 \mathrm{mg}$ & $55.7(8.8)$ & $\downarrow 6.3$ (2.8)\#\# & $\downarrow 6.8$ (2.7)\#\# \\
\hline & $2 \mathrm{mg}$ & $61.8(8.2)$ & $10.0(3.8)$ & $6.7(2.6)$ \\
\hline \multirow[t]{2}{*}{ Slept Well: } & $0 \mathrm{mg}$ & $67.4(6.6)$ & $\downarrow 53.7$ (6.4)\#\# & $60.2(6.3)$ \\
\hline & $2 \mathrm{mg}$ & $65.9(6.4)$ & $53.7(6.7)$ & $61.8(6.2)$ \\
\hline \multirow[t]{2}{*}{ Clearheaded: } & $0 \mathrm{mg}$ & $71.6(6.2)$ & $\downarrow 58.6(7.7) \# \#$ & $\downarrow 55.6(7.7) \# \#$ \\
\hline & $2 \mathrm{mg}$ & $73.6(5.5)$ & $61.1(7.0)$ & $60.0(6.4)$ \\
\hline \multirow[t]{2}{*}{ Woke Often: } & $0 \mathrm{mg}$ & $22.4(7.1)$ & 个 33.7 (6.4)\# & $28.8(8.1)$ \\
\hline & $2 \mathrm{mg}$ & $27.1(5.6)$ & $43.9(7.6)$ & $30.9(7.1)$ \\
\hline \multirow[t]{2}{*}{ Hours Slept: } & $0 \mathrm{mg}$ & $7.2(0.2)$ & $\downarrow 6.7(0.2) \# \#$ & $6.9(0.3)$ \\
\hline & $2 \mathrm{mg}$ & $7.4(0.2)$ & $6.6(0.2)$ & $6.9(0.2)$ \\
\hline \multirow[t]{2}{*}{ Calories (kcal): } & $0 \mathrm{mg}$ & $4073(384)$ & $\downarrow 2553$ (170)\#\# & $\downarrow 2689$ (175)\#\# \\
\hline & $2 \mathrm{mg}$ & $4017(273)$ & 2508 (309) & $2722(235)$ \\
\hline \multirow[t]{2}{*}{ Eating Occasions: } & $0 \mathrm{mg}$ & $9.3(0.7)$ & $\downarrow 6.1(0.6) \# \#$ & $\downarrow 6.3(0.6) \# \#$ \\
\hline & $2 \mathrm{mg}$ & $9.8(0.4)$ & $6.6(0.9)$ & $6.5(0.6)$ \\
\hline \multirow[t]{2}{*}{ DSST (\% correct) } & $0 \mathrm{mg}$ & $81.5(3.6)$ & ศ 86.5 (3.8)\# & 个 85.6 (3.6)\# \\
\hline & $2 \mathrm{mg}$ & $80.9(4.3)$ & $87.0(3.7)$ & $86.6(4.0)$ \\
\hline \multirow[t]{2}{*}{ DAT (max speed) } & $0 \mathrm{mg}$ & $424(24)$ & 个454 (25)\# & $430(29)$ \\
\hline & $2 \mathrm{mg}$ & $436(29)$ & $472(28)$ & 个 $474(27)^{* *}$ \\
\hline Tobacco Cigarettes: & $0 \mathrm{mg}$ & $6.4(0.7)$ & 个7.9 (0.6)\#\# & 个 $8.3(0.5) \# \#$ \\
\hline
\end{tabular}

This article is protected by copyright. All rights reserved. 


\begin{tabular}{ccc|cc} 
& $2 \mathrm{mg}$ & $6.2(1.1)$ & $7.5(0.8)$ & $8.3(0.8)$ \\
Cigarette Craving: & $0 \mathrm{mg}$ & $49.1(10.0)$ & $\downarrow 32.6(10.9) \# \#$ & $\downarrow 32.9(10.6) \# \#$ \\
& $2 \mathrm{mg}$ & $45.4(11.1)$ & $\uparrow 54.0(11.4)^{* *}$ & $\uparrow 47.6(11.6)^{* *}$
\end{tabular}

Note: Data in parentheses represent standard error of the mean; maximum rating $=100 \mathrm{~mm}$. DSST: Digit Symbol Substitution Task. DAT: Divided Attention Task; max speed unit = pixels/sec.

Asterisks represent significant differences between guanfacine and placebo $* \mathrm{p}<0.05, * * \mathrm{p}<0.01$, and the arrow signs indicate the direction of the effect. Hashtag represent significant differences between cannabis administration and abstinence (mean days 1-2 and days 3-4) under placebo guanfacine conditions \# $\mathrm{p}<0.05$, \#\# $\mathrm{p}<0.01$. All data points represent a mean of all participants $(n=15)$ except for those related to tobacco cigarettes ( $n=12$ cigarette smokers). 
TABLE 4: Frequency of Side Effects

\begin{tabular}{l|cc|cc} 
& \multicolumn{2}{|c|}{ Outpatient } & \multicolumn{2}{c}{ Inpatient } \\
Guanfacine Dose (mg) & 0 & 2 & 0 & 2 \\
\hline Headache & $2(2)$ & $1(1)$ & $6(3)$ & $4(2)$ \\
Gastrointestinal upset & $8(4)$ & $2(1)$ & $3(2)$ & $2(2)$ \\
Fatigue & $10(3)$ & $20(5)$ & $0(0)$ & $2(2)$ \\
Body pain & $4(3)$ & $1(1)$ & $1(1)$ & $4(3)$ \\
Dry Mouth & $4(3)$ & $11(3)$ & $0(0)$ & $0(0)$ \\
& & & & \\
\hline
\end{tabular}

Note: Data reflect the number of times each symptom was reported during the outpatient phase (10 days/dose) and inpatient phase ( 9 days/dose) as a function of guanfacine dose; the number of participants reporting each symptom is in parentheses $(\max =15)$. 
Fig. 1

$$
\text { Irritable }
$$

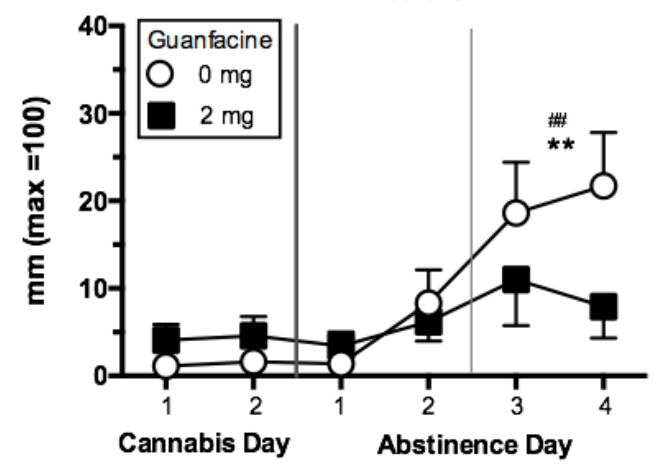

\section{Fig. 2 Sleep Efficiency}
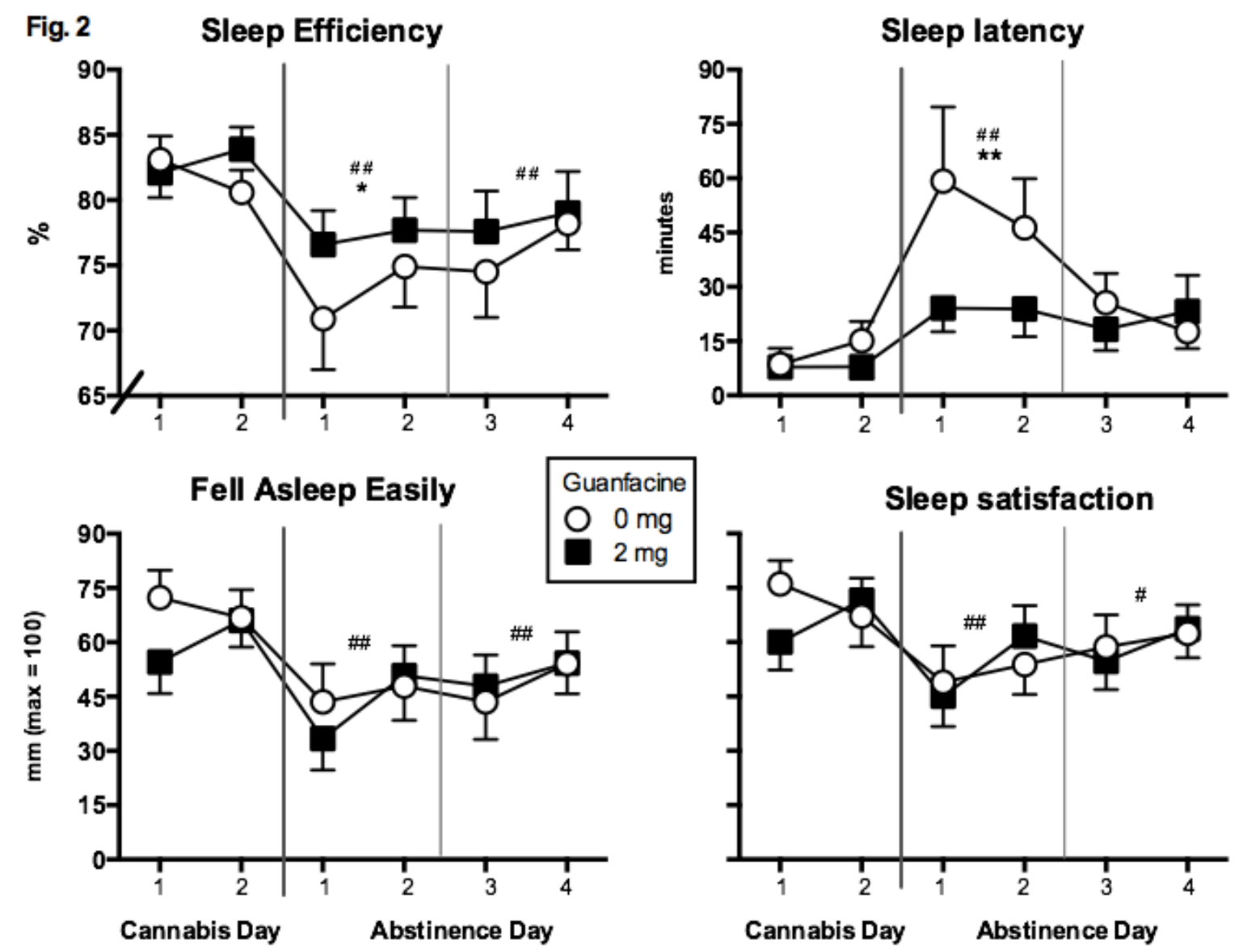

This article is protected by copyright. All rights reserved. 
Fig. 3 Systolic Pressure

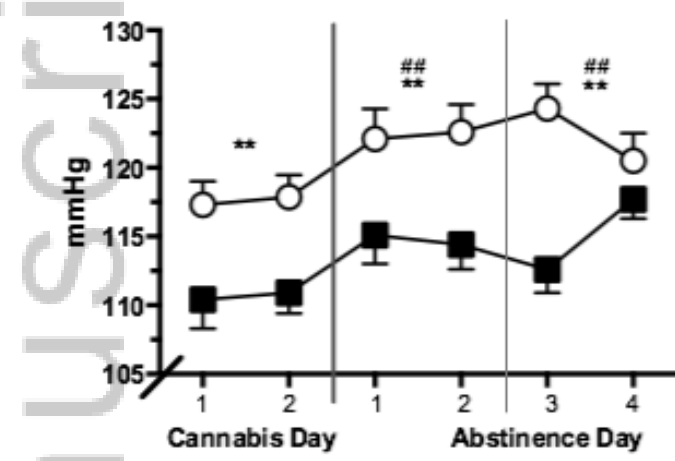

Diastolic Pressure

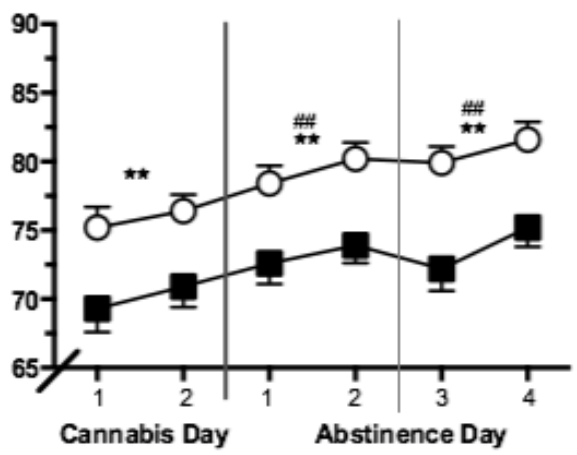

Heart rate

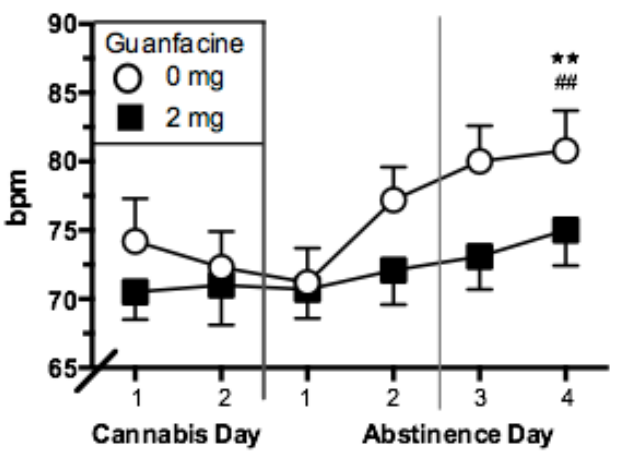

This article is protected by copyright. All rights reserved. 


\section{Figure Legends}

Figure 1: Mean effects on peak cluster ratings of irritability during cannabis administration (5.6\%) and during cannabis abstinence as a function of guanfacine dose. Maximum score for ratings $=100$ $\mathrm{mm}$. Each graph represents data collected in 15 participants. Asterisks indicate a significant difference between guanfacine and placebo in two blocks: days 1-2 of cannabis abstinence and days 3-4 of abstinence $(* \mathrm{p}<0.05 ; * * \mathrm{p}<0.01)$. Number signs indicate a significant difference during cannabis administration and during cannabis abstinence under placebo medication conditions (\# p < 0.05; \#\# $\mathrm{p}<0.01)$. Error bars represent \pm SEM.

Figure 2: Mean effects on objective (top panels) and subjective (bottom panels) measures of sleep during cannabis administration (5.6\%) and during cannabis abstinence as a function of guanfacine dose. See Figure 1 for details.

Figure 3: Mean cardiovascular data during cannabis administration (5.6\%) and during cannabis abstinence as a function of guanfacine dose. See Figure 1 for details. 


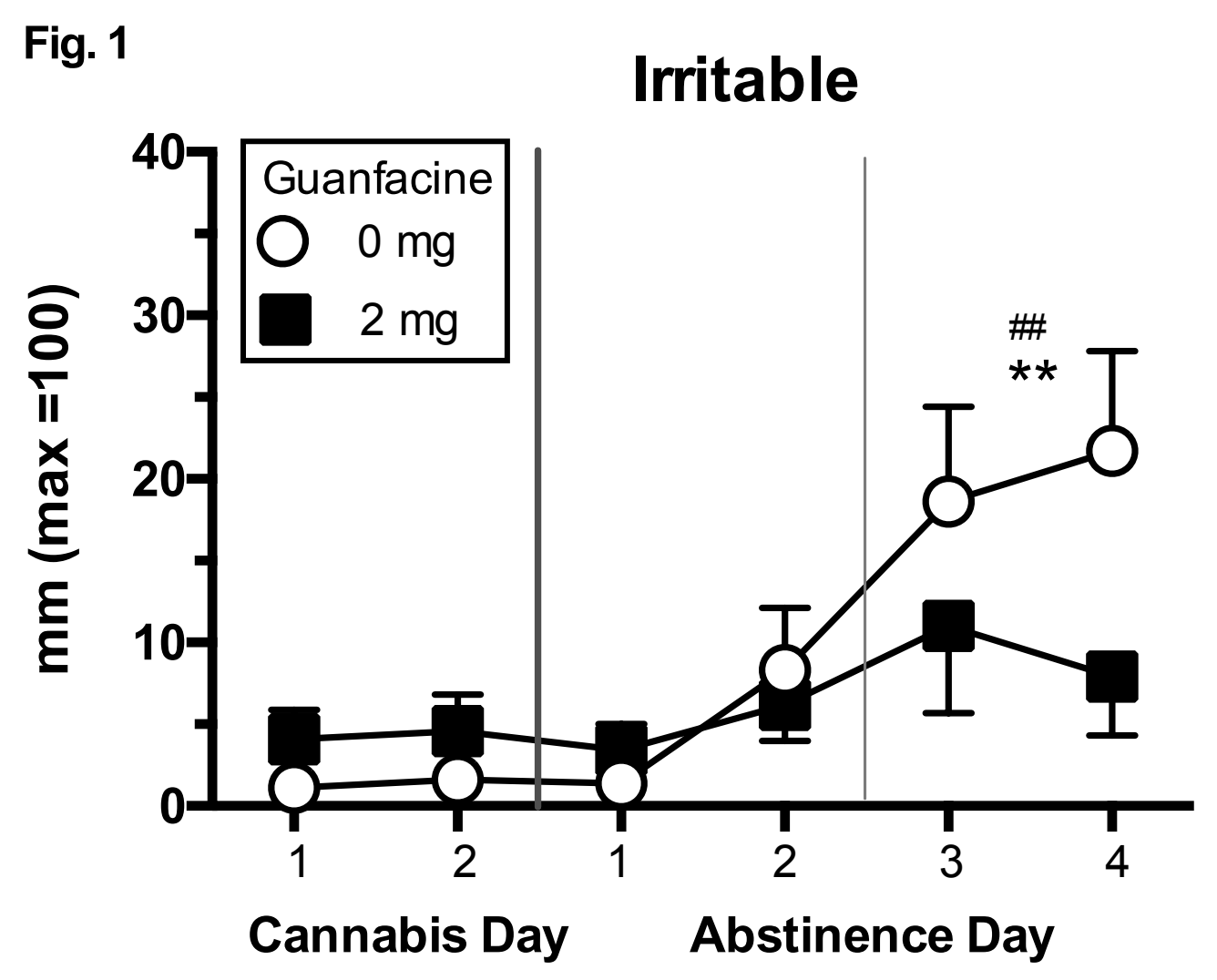


Fig. 2 Sleep Efficiency

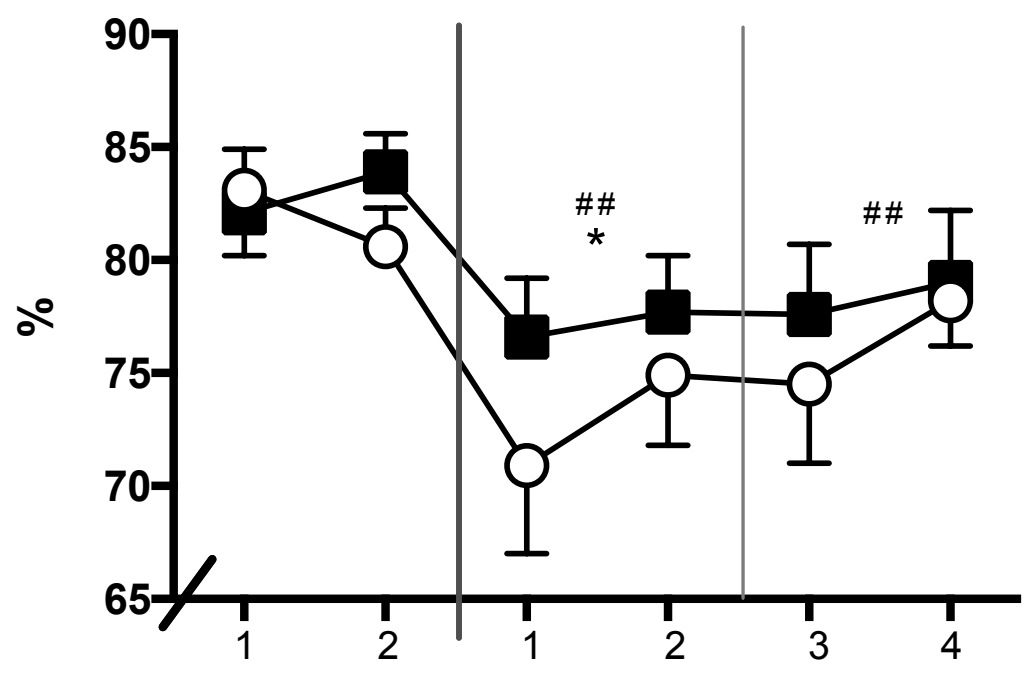

Fell Asleep Easily

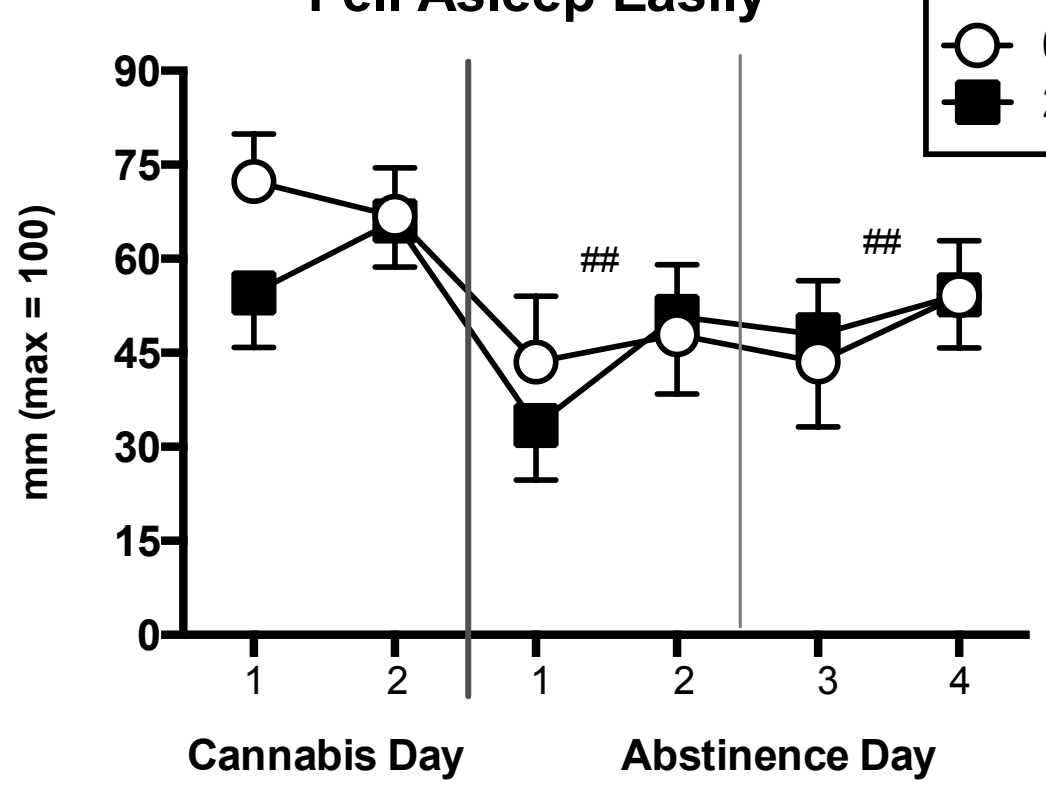

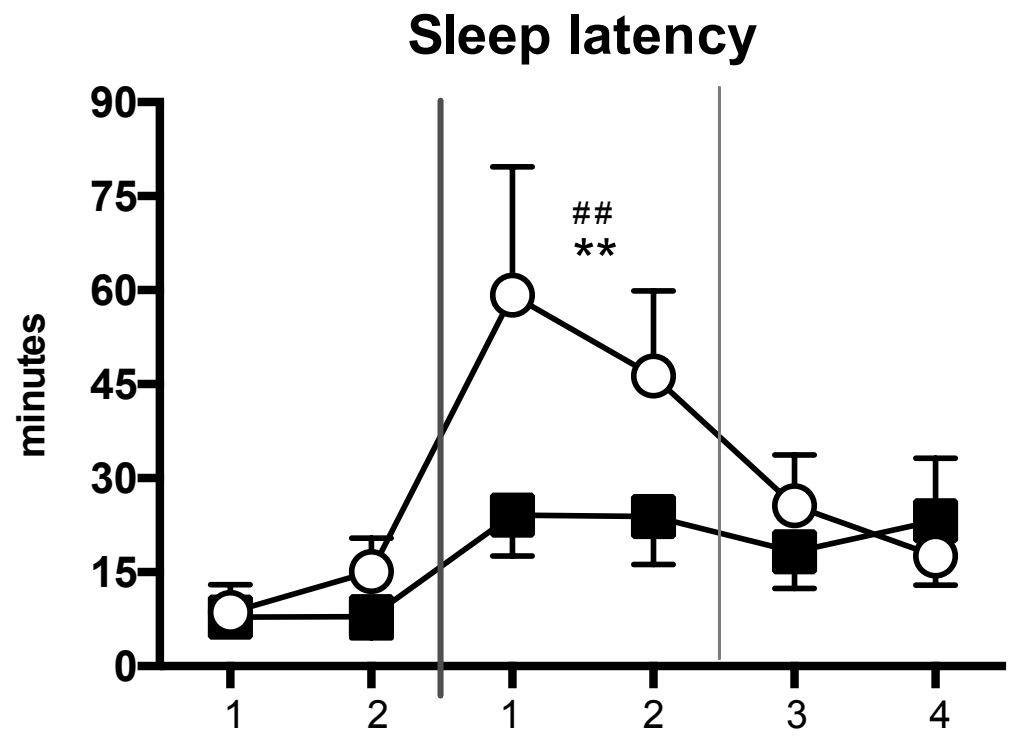

Sleep satisfaction

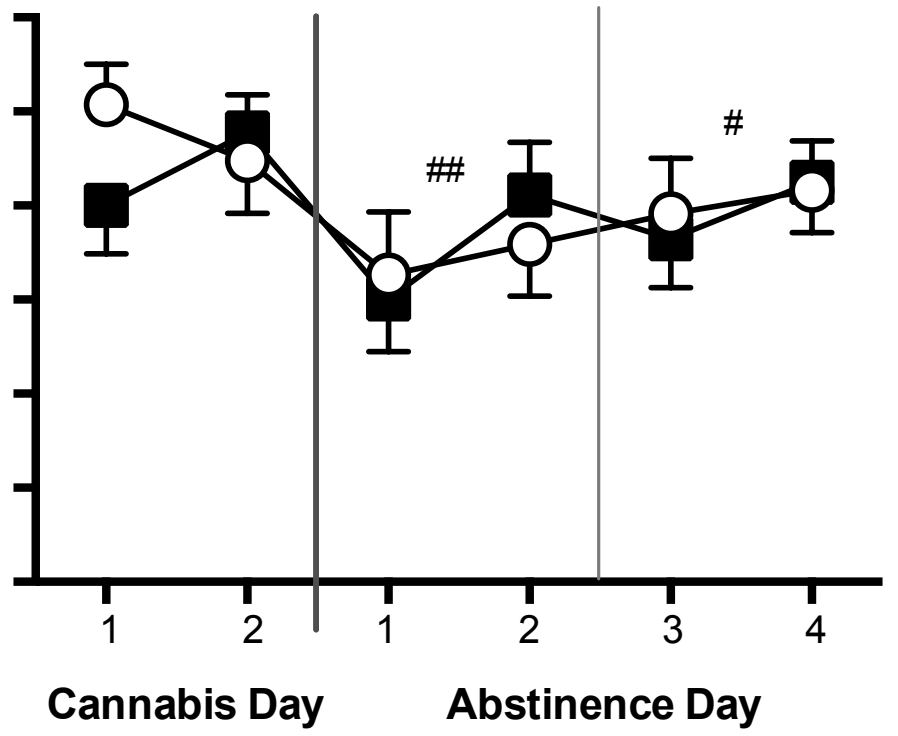




\section{Fig. 3 Systolic Pressure}

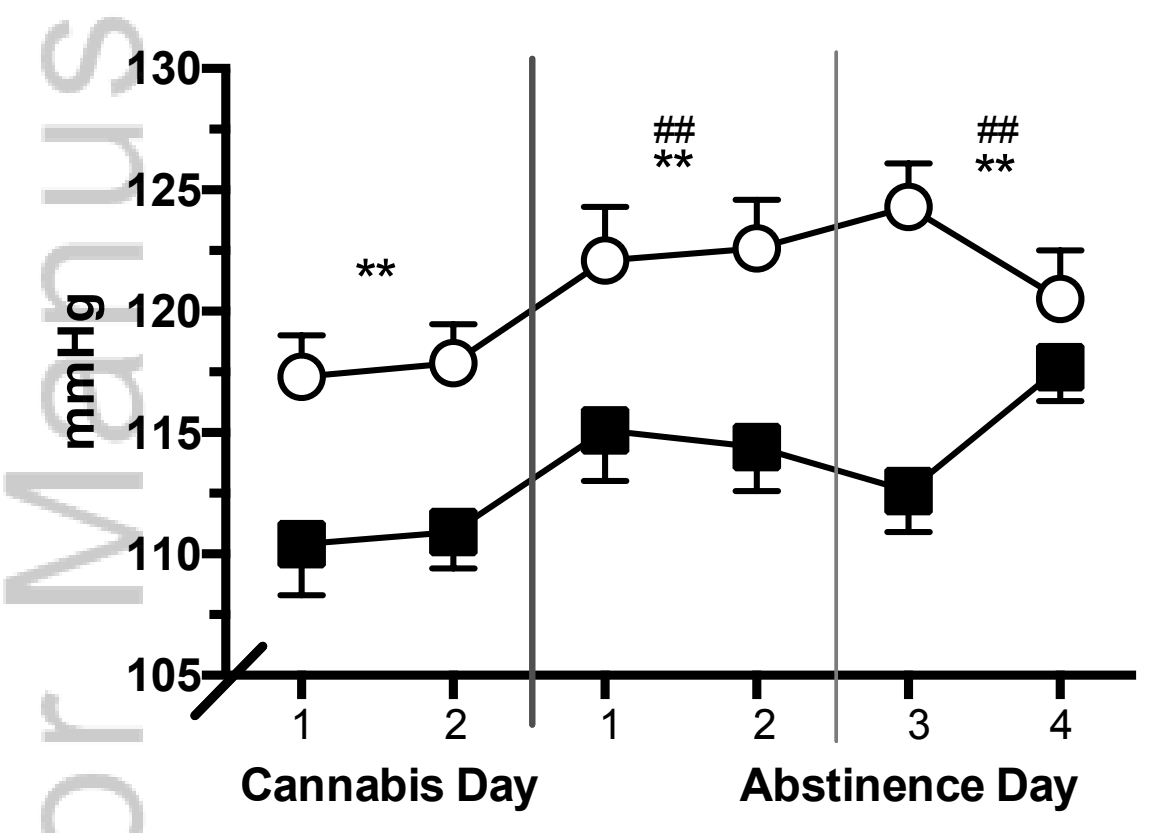

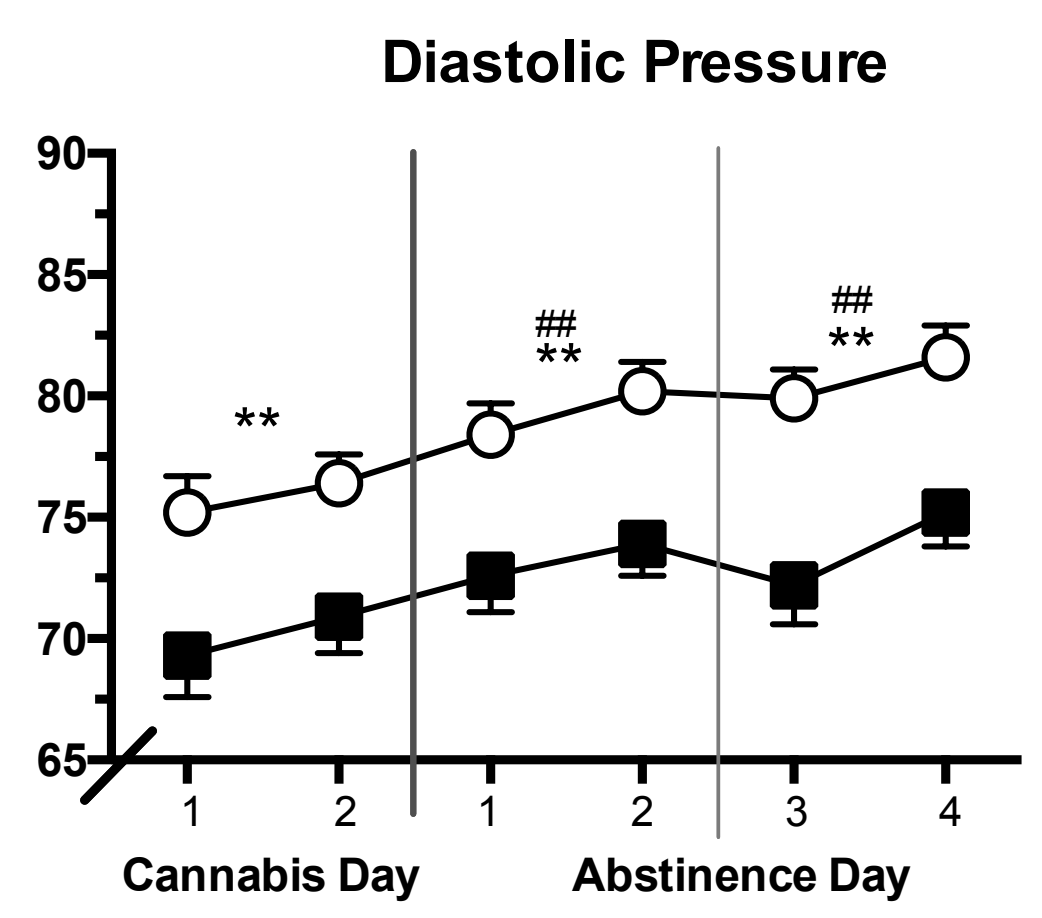

Heart rate

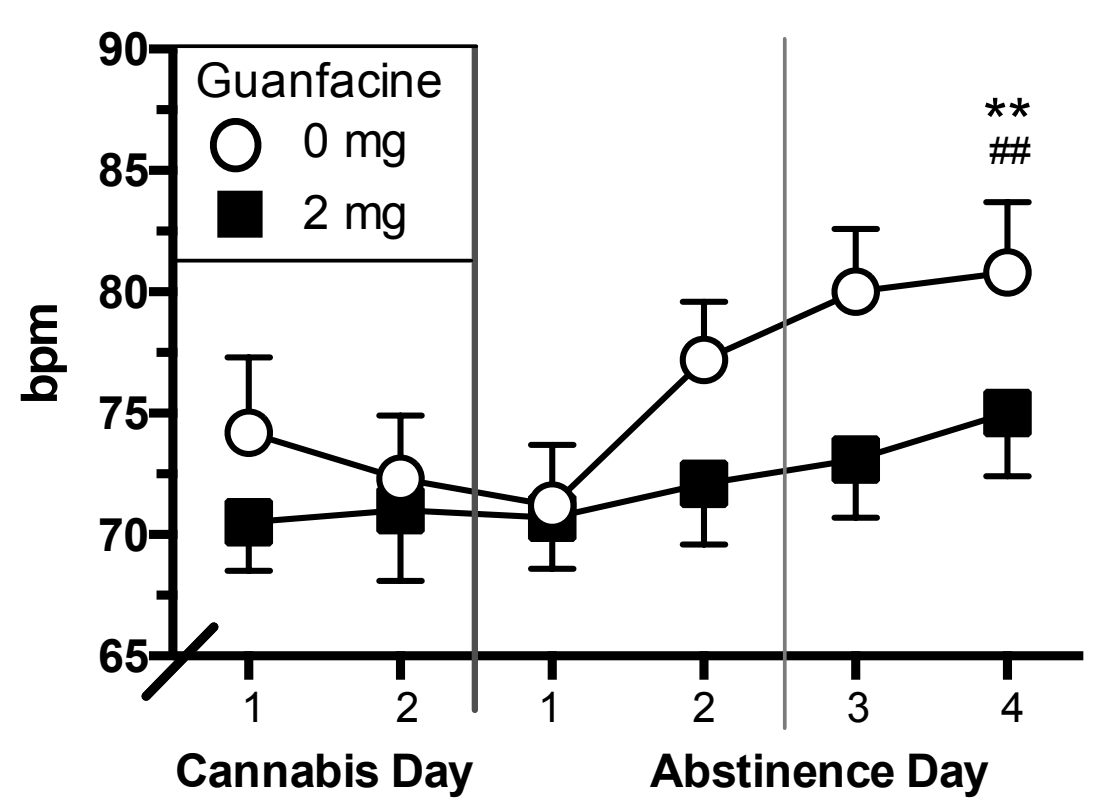




\section{University Library}

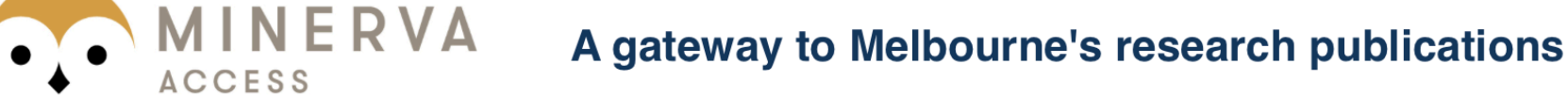

Minerva Access is the Institutional Repository of The University of Melbourne

\section{Author/s:}

Haney, M;Cooper, ZD;Bedi, G;Herrmann, E;Comer, SD;Reed, SC;Foltin, RW;Levin, FR

Title:

Guanfacine decreases symptoms of cannabis withdrawal in daily cannabis smokers

\section{Date:}

2019-07-01

\section{Citation:}

Haney, M., Cooper, Z. D., Bedi, G., Herrmann, E., Comer, S. D., Reed, S. C., Foltin, R. W. \& Levin, F. R. (2019). Guanfacine decreases symptoms of cannabis withdrawal in daily cannabis smokers. ADDICTION BIOLOGY, 24 (4), pp.707-716. https://doi.org/10.1111/ adb.12621.

Persistent Link:

http://hdl.handle.net/11343/283915 